\title{
LA EDUCACIÓN DE NIÑAS AMUZGOS \\ EN EL ESTADO DE OAXACA (MÉXICO) ${ }^{1}$
}

\author{
Anita Gramigna ${ }^{2}$
}

\begin{abstract}
La educación de niñas amuzgos en el estado de Oaxaca (México)
Resumen: Este trabajo es un resumen de la investigación realizada durante los años 2010-14 entre el pueblo Amuzgo de San Pedro de Oaxaca ${ }^{3}$. El escrito, para el que se utilizan instrumentos etnográficos, se propone como objetivo reflexionar acerca de la formación, los procesos de construcción del conocimiento y sobre el valor cognitivo y epistemológico de la relación (LéviStraus 1978: 48). Proponemos una obra de autohermeneusis, de análisis de la direccionalidad de los puntos de vista, de descubrimiento de los presupuestos implícitos, de verificación de los procesos científicos en la investigación. Por esta razón la nuestra es una aproximación de tipo hermenéutico.
\end{abstract}

Palabras clave: Epistemología, formación, relación, hermenéutica, etnografía, conocimiento.

\section{The Education of Amusgos Girls in the State of Oxaca (Mexico)}

Abstract: This essay presents the results of the research we carried out on the Amusgo people of San Pedro, in Oxaca, between 2010 and 2014.

This work, for which we use ethnographic instruments, aims to reflect on the formation, on the processes of building knowledge, and on the cognitive and epistemological value of the relationship (Lévi-Straus 1978: 48). We suggest a written piece of auto-interpretation, by analysing the points of view, the implicit premises and the scientific processes of research. For this reason, our study perspective is hermeneutic.

Key words: Epistemology, formation, relation, hermeneutics, ethnography, knowledge.

\section{Introducción}

Son ya algunos años, en diversos viajes y estancias de estudio o académicos, que transito por estos paisajes culturales. Estuve un largo período sabático en Oaxaca, antes, después y durante el cual pude realizar muchas y repetidas visitas al mundo indígena, y en particular al pueblo amuzgo, entre los Tzjon Non, el pueblo de los tejidos. Fueron estancias académicas sucesivas durante las cuales conviví con algunas comunidades

\footnotetext{
${ }^{1}$ Fecha de recepción: 10/09/2015.

Fecha de aceptación: 05/10/2015.

${ }^{2}$ Profesora Titular de Pedagogía General, Departamento de Humanidades, Universidad de Ferrara, Ferrara, Italia; $\bowtie$ grt@unife.it.

${ }^{3}$ El estado de Oaxaca está situado al sureste de México. Colinda al norte con Veracruz y Puebla, al este con Chiapas, al oeste con Guerrero y al sur con el océano pacífico.
} 
indígenas del estado de Oaxaca. Por ello el trabajo consiste en un análisis de la educación que adquieren las niñas amuzgo mientras aprenden a tejer sus huipiles, símbolo de su identidad lingüística y cultural. Se trata de un saber abstracto que se construye en la práctica concreta y en un conocimiento sistemático que artísticamente representa una visión del mundo. Los huipiles son formas de conocimiento organizados según una precisa visión del mundo y de acuerdo a una estructura compleja que requiere de saberes geométricos, matemáticos, religiosos. Un pensamiento que es místico, y también social, abstracto, lírico y ritual, y que está en estrecha relación con la naturaleza. Se sabe ${ }^{4}$ que este pueblo llegó procedente de las islas más alejadas del Pacífico buscando una tierra donde establecerse. $N n$ `anncue, que es el nombre con el que se les conoce, significa "en medio del mar".

Los $\mathrm{Nn}$ `anncue llegaron a la costa del hoy estado mexicano de Oaxaca y empezaron a desplazarse para llegar al lugar que sería su patria, pero lo hicieron acosados, perseguidos y amenazados por un águila con dos cabezas ${ }^{5}$. El mito del águila bicéfala constituye un claro ejemplo de conservación y reproducción de su tradición histórica y cultural a través del tejido. En éste se narra el mito de los orígenes a través de la escritura no alfabética. Su escritura originaria, de la que los tejidos son una huella, era jeroglífica. Desde siempre estas comunidades son famosas por la calidad artística de sus tejidos y la finura de las imágenes que los decoran. Los habitantes del poblado de San Pedro Amuzgos, quizás la municipalidad amuzga más grande de Oaxaca, se llaman a sí mismos Tzjon Non, que significa "pueblo de tejidos, hilo delicado, ovillo". Hoy esta actividad es la más importante fuente de ingresos de las familias que, hasta hace pocos años, vivían una economía basada solamente en la agricultura. Normalmente es la mujer la que teje y que se dedica a todas las labores domésticas, además del cuidado de los hijos, mientras que el hombre se ocupa de la agricultura; pero dado que el comercio de los tejidos representa una fuente cada vez más importante de ingresos, desde hace algunos años muchos hombres dedican también parte de su tiempo a tejer. La práctica del tejido se

\footnotetext{
${ }^{4}$ Este relato lo escuché, con variaciones poco significativas, de diferentes personas, incluido Odilón.

${ }^{5}$ El águila bicéfala representa uno de los motivos menos claros entre el artesanado indígena en el estado de Oaxaca, pero lo encontramos también en el pueblo amuzgo del estado de Guerrero y en Guatemala. Se trata de una figura difícil de ejecutar que requiere cierto nivel formativo.
} 
inicia a temprana edad; vi a niñas de cuatro años jugar con su pequeño telar y tejer pañuelos más o menos regulares con el algodón de desperdicio. Pero la educación formal empieza hacia los seis años y se vuelve más exigente y estructurada a los ocho años de edad. Al principio la niña debe aprender a colocar los bastones que formarán su pequeño telar con la cintura que correrá en torno a sus flancos; luego a ampliar el tejido, a preparar la trama, y finalmente a tejer figuras simples. Suele ser la madre la encargada de enseñar a las pequeñas el difícil arte del tejido, luego de una explícita solicitud, pero con frecuencia es la abuela quien a lo largo del tiempo ha adquirido las técnicas más finas y que recuerdan el significado de los símbolos ancestrales. Es a través de este conocimiento complejo que las mujeres muestran en sus propias indumentarias la identidad individual, su pertenencia étnica, la adhesión cultural a los valores de su comunidad. Lo tejidos de los Tzjon Non son construcciones simbólicas de la vida social, espiritual, educativa. Son una técnica de conservación de su cultura, testimonio de un conocimiento integral que comprende las instancias históricas, biológicas, artísticas, matemáticas, geométricas, filosóficas. La trama de estos tejidos es lógica y refleja una manera de vivir.

El gobierno de cada comunidad se deposita en un consejo de ancianos; cada autoridad se ocupa de una tarea precisa que va desde la seguridad hasta el juicio sobre algunas disputas, y al mantenimiento de los espacios públicos. Otro grupo de personas importantes, principales, son los mayordomos, quienes se ocupan de cuidar, cada uno, una imagen sagrada, un Cristo, una Virgen, o un Santo, llevándoles velas y flores, y cuidando de sus vestimentas. Estos mayordomos organizan las fiestas religiosas del patrón del que se ocupan llevando, con frecuencia, la carga económica que implica. Existen orgaizaciones espontáneas de ayuda mutua entre parientes y amigos que permite a todos los miembros de la comunidad atender los problemas más urgentes y organizar la festividad del santo que está bajo su cuidado. Las más comunes enfermedades se atienden en casa con la farmacopea tradicional y de acuerdo a los principios de la medicina ancestral. Algunos padecimientos, por ejemplo el espanto ${ }^{6}$, requieren de la intervención especializada de un experto, el curandero, quien es un sabio y médico tradicional, al que

\footnotetext{
${ }^{6}$ Se trata de una especie de choc producido por un susto que bloquea al alma de la persona en el mismo sitio en que sucedió el choc.
} 
llaman tzan t'ì o tzan kalwa, que se sirve de ritos especiales. Asistimos a una ceremonia de curación de un espanto: la curandera recitaba fórmulas especiales y quemaba hierbas purificadoras exactamente en el lugar donde la señora afectada por el espanto había encontrado una serpiente muy venenosa. Al término de la ceremonia ofrecieron comida y bebida tradicionales. Las ceremonias fúnebres duran 80 días, al término de los cuales se piensa que el difunto ya llegó al lugar donde reposan los muertos: el Mictlán. Las mujeres son sepultadas con todos sus huipiles $^{7}$ y sus joyas.

Las muchachas se casan entre los 15 y los 17 años, los chicos un par de años mayores. Son familias que, aconsejadas por el sacerdote, concertan los matrimonios, pero esta costumbre está cambiando hacia una cierta libertad de parte de los jóvenes que, no obstante, deben contar con la aprobación de sus padres. La religión recoge creencias prehispánicas en un profundo sincretismo con el cristianismo del cual se exhaltan los valores que sostienen todas las prácticas cotidianas. Las ceremonias tienen un carácter propiciatorio y siguen el ritmo de la agricultura, o el de la caza, o del ganado. Todo está permeado por un gran sentido de trascendencia que representa solamente el escenario en el que se "teje" la relación con lo espiritual ${ }^{8}$.

Oaxaca es uno de los estados más ricos del mundo en cuanto a diferencia cultural: son 16 los grupos entolingüísticos (cfr. Anaya 1987). Las comunidades indígenas son famosas por la calidad de sus productos artísticos y por una artesanía que dentro de su extraordinaria variedad es considerada por algunos como la más bella del mundo. Las culturas indígenas de Mesoamérica, particularmente la Amuzga, son muy delicadas, ricas y complejas que no pueden ser valoradas ni medidas en términos de "civilidad" o "progreso", porque éstas son categorías de lectura inadecuadas para captar su peculiaridad; tampoco se pueden definir por los índices de escolaridad, ni en general, con nuestros parámetros socioculturales.

\footnotetext{
${ }^{7}$ Son trajes tradicionales elaborados en el telar de cintura en tres piezas unidas con un delicado bordado a mano. La parte principal, llamada pechera, es la que lleva los adornos más elaborados.

${ }^{8}$ Numerosos testimonios de lo que suscintamente hemos descrito se pueden encontrar en el Museo Comunitario Amuzgo di Xochistlahuaca, en el estado de Guerrero.
} 
He estudiado la educación "tradicional" que reciben las niñas en la comunidad y que se compara con la instrucción formal otorgada por el Estado en las escuelas primarias bilingües. Éstas deberían enseñar la lengua indígena de la comunidad en la que reside la escuela y también el español. Para esto, en el año 2000 se instituyó en Oaxaca la Escuela Normal Bilingüe e Intercultural con la intención de formar maestras y maestros capaces de trabajar tanto en una de las 16 lenguas indígenas -la lengua madre del docente-, como en español. En el estado de Oaxaca son dos millones los habitantes que hablan una lengua indígena (Blancas 2010).

He analizado también las prácticas educativas que determinan la cotidianeidad y el desarrollo formativo de las niñas, para obtener un concepto acerca del conocimiento y de la formación de carácter holístico que pretende ser una sabiduría marcada por un rasgo espiritual. La educación de las pequeñas se considera mucho más importante que la de los varoncitos porque se piensa que las mujeres están más cerca que los hombres de "la fuente del espíritu" que es Dios. Son las mujeres, de hecho, quienes dan la vida, quienes hacen nacer a los niños, los guían en sus primeros momentos formativos y quienes se ocupan de su educación. "Por esto, porque está más cerca de la fuente de energía divina -nos asegura una joven madre- la educación de las niñas es mucho más severa y vigilada, porque las mujeres deben tener un conocimiento mayor, deben saber más cosas". Existe un Dios único, que es el gran espíritu, El Taa, que anima, con su propia energía vital, Zatzrom, a todas las cosas y seres del mundo. La caracterización epistémica de esta educación, me parece que está dada por su altísima densidad relacional. Es ésta la característica de la gnoseología amuzga. El saber, para los amuzgos ${ }^{9}$, es sabiduría, o bien una relación interactiva de compenetración con el mundo, mediante un conocimiento profundo de la energía divina que lo anima y que anima, sin solución de continuidad, a todos los seres vivientes, los elementos del mundo natural, los objetos. Este pueblo practica ritos prehispánicos en honor de las fuerzas de la naturaleza, como en tiempos de la agricultura original. Las imágenes y los símbolos de tales ritos son representados en los tejidos, que fungen como texto escrito, conservación y divulgación cultural (Frutiger

\footnotetext{
${ }^{9}$ El pueblo amuzgo vive en los estados de Guerrero y de Oaxaca. En este último, la población se concentra en las comunidades de San Pedro Amuzgo y de Santa María Ipalpa.
} 
1981). Con esta práctica, las niñas aprenden la matemática en forma aplicada, pero a partir de la cosmovisión de su pueblo. La manera de contar, clasificar, medir, está estrechamente vinculada con el contexto natural y cultural. No existe una enseñanza abstracta ni mecánica de los números, de las formas y de su relación con el espacio. El tejido, arte entre los más antiguos del México precolombino, es la actividad educativa principal para las niñas amuzgos, porque involucra contenidos, prácticas y valores de su identidad cultural y -ésta es mi tesis-condiciona y forma su cognición específica.

\section{La perspectiva epistemológica y la metodología}

Estas páginas son el resultado de una búsqueda de la epistemología que se sirve, entre otros, de los instrumentos de búsqueda de la etnografía y que nos impone una mirada "cualitativa" sobre un mundo, en todos sentidos, muy lejano de nosotros, de nuestra lógica y de nuestras tradiciones educativas. Las micronarraciones que recogí a lo largo de numerosas entrevistas estructuradas y semiestructuradas representan un hermeneuin, un anuncio que debe ser interpretado, para llegar al proceso cognitivo (cfr. Vattimo 1989, 1994). Por tanto, el fondo epistemológico (cfr. Gadamer 1972, 1973) es hermenéutico. He tratado de establecer una relación dialógica con la realidad que estábamos indagando, una interacción entre preguntas, a veces también calladas o sólo sugeridas, y respuestas: un diálogo vuelto hacia la integración de los respectivos horizontes de significado ${ }^{10}$. Por este motivo la aproximación adoptada valora una estética de tinte etnográfico, porque ha buscado precisar el valor heurístico de la diferencia, de lo cotidiano, de lo cercano, así como de la familiaridad, de lo extraordinario, de lo lejano (cfr. Valleriani 2003). Estudiar el fenómeno educativo en este sentido implica necesariamente identificar la diversidad y la naturaleza de las relaciones entre ellos, en la determinación trans-formativa de los eventos que tienen relevancia formativa, de las situaciones, de los sujetos, de las comunidades ... Una epistemología que interpreta la formación, lato sensu, en tanto que

\footnotetext{
${ }^{10}$ Aquí vemos clara la lección de Gadamer, que sirve de trasfondo a nuestra reflexión.
} 
relación entre diferencias, a la luz del paradigma intercultural, como su principal instrumento de trabajo. O sea, para una reflexión pedagógica que tiene grandes repercusiones sobre lo pragmático de la acción y del proyecto educativo, en un desarrollo circular teoría-práctica sin solución de continuidad. Se trata de una hermenéutica epistemológica, o bien (cfr. Escolano Benito y Gramigna 2004), de una lectura de la procesualidad dinámica que es la relación y que subyace a la educación.

La muestra de entrevistados estuvo compuesta de alrededor de 40 personas de las cuales 35 tejedoras ( 5 ancianas y 10 niñas, 20 adultas) y 5 personas que desempeñan roles diversos en la comunidad de San Pedro Amuzgos. Los entrevistados fueron escogidos en base al perfil que nos interesaba para fines de investigación o para la comprensión de ese particular contexto educativo. Entrevisté a tejedoras con sus hijos, con sus maridos y sus familiares. Las interrogué sobre el significado de aquellas bellísimas figuras que, en su lengua, significan "símbolo". Conversé con maestras y maestros, así como con los coordinadores de los maestros indígenas, a los que agradecemos, con las autoridades académicas y colegas antropólogos que nos abrieron muchas puertas. Particularmente tuvimos el apoyo, la mediación y la ayuda de Odilón Merinos, joven experto de tejidos amuzgos, al que previamente tuve como estudiante y que nos introdujo en los secretos, en la lengua (cfr. Stewart y Stewart 2000) y en la cultura amuzga de la comunidad de San Pedro.

Los amuzgos pertenecen al grupo lingüístico Savizaa, emparentada con el Meteco, el Cuicatero y el Trique. Se trata de una lengua tonal; esto significa que palabras semejantes tienen significados diferentes según el nivel, o tono de la voz. Los sonidos son menos importantes que la melodía. Es en la melodía que se distingue el sentido de un discurso, de una frase o de una simple palabra ${ }^{11}$. Para los europeos la lengua presenta

\footnotetext{
${ }^{11}$ El artículo 2, par. A. de la Constitución Política de los Estados Unidos Mexicanos, modificada en abril del 2001 reconoce el derecho de los pueblos indígenas a la propia autoeterminación y, en consecuencia, a preservar y enriquecer su lengua, junto a todos los elementos que caracterizan su riqueza cultural. Específicamente, la Ley General de los Derechos Lingüísticos de los Pueblos Indígenas (marzo 2003) fue promulgada para "proteger" y "promover" las lenguas indígenas consideradas como patrimonio cultural de la Nación. Según el artículo 8 de dicha Ley, ninguna persona podrá ser discriminada a causa de la lengua que habla. Cfr. INALI: 2008. Base de datos. México: Dirección de Tecnologías de la Información, Instituto Nacional de Lenguas Indígenas. http://www.inegi.gob.mx (Consulta: Marzo 2008); http://www.iadb.org/sds/ind/ley/leyn/datamap.cfm (Consulta: Mayo 2008).
} 
muchas dificultades de pronunciación, entre otras cosas porque con frecuencia las palabras empiezan con consonantes diferentes de lo que sigue. Muchos indígenas -gran parte de los adultos- no hablan ninguna de las lenguas europeas, en el mejor de los casos, los niños que van a la escuela primaria bilingüe conocen un poco el español. La traducción al español que nos hizo Odilón fue, por tanto, esencial. Existen cuatro variantes de la lengua Amuzgo: septentrional, meridional, bajo y alto oriental. Las personas entrevistadas pertenecen a este último grupo linguístico que se ubica territorialmente en el estado de Oaxaca. Recogimos muchos documentos que fueron catalogados y estudiados a la luz de su contexto cultural y de las implicaciones educativas que nos podían sugerir. Fueron entrevistas estructuradas y semiestructuradas de autonarraciones, historias de vida, figuras, tejidos, vestidos, rebozos e instrumentos para el tejido y para hilar y dardar el algodón; en fin, materiales, pigmentos e insectos para dar color a los hilos de algodón.

La atención al detalle específico, a lo singular y peculiar de los datos es quizás la nota importante de esta primera fase de la investigación, que se basó en un andamiaje de tipo inductivo orientado a formular y reformular por aproximaciones sucesivas las interpretaciones. El levantamiento de datos consistió en: observaciones y anotaciones sistemáticas, el volver a los lugares investigados para controlar las interpretaciones y para sucesivas profundizaciones que, poco a poco, se hacían necesarias. Las tecnologías adoptadas fueron: diario de campo, rejillas de observación de las manufacturas, indicios para las entrevistas, fichas para el análisis de los documentos y las informaciones obtenidas. Los datos fueron estudiados tanto en su singularidad simbólica y fenomenológica, como en la perspectiva sistémica socio-antropológica de su pertenencia cultural e histórica. Con frecuencia me di cuenta que aún en la diversidad de los hallazgos y documentos, existían recurrencias que parecían significativas. Creímos que tales recurrencias podrían constituir principios narrativos de explicación de los fenómenos que estábamos estudiando. Los detalles se han examinado en su valor cualitativo, lo que significa que privilegié las relaciones de significado que podían sugerir esos datos. Poner atención a las cualidades de los fenómenos implica concentrarse en las relaciones de sentido que unen los datos en un conjunto significante. Estoy consciente de que la 
operación que definimos como "hermenéutica aplicada" es artificial, que representa una construcción tecnológica (cfr. Geertz 1987, 1995, 2001). He tratado de recoger el sentido de las representaciones compartidas por los miembros de la comunidad amuzga de los Tzjon Non, la cual nos ha hecho partícipes de su saber, al menos hasta donde nuestra extranjería lo permitió.

\section{El saber maravilloso}

No existe una escuela o un centro artesanal donde se enseñe institucionalmente el tejido de cintura. El aprendizaje se da en casa, de acuerdo a la práctica del aprender haciendo; las indicaciones y los ejemplos se transmiten oralmente porque no existen escritos o diseños de procedimientos a reproducir.

El proceso requiere la adquisición técnico-teórica de diferentes niveles de complejidad. Al principio la niña aprende a tejer figuras pequeñas (ljeii cach 'uu) que se caracterizan, además de sus dimensiones, por la sencillez de su ejecución. Estas figuras son normalmente: la luciérnaga (cat'cuee) compuesta de seis triángulos dispuestos de tal manera que dejan en el centro un espacio de tejido-fondo de la misma dimensión y forma. Luego está el pedazo de jabón (ta xapo), la piedra (tatsjo'), el sapo (tyosaa), el escarabajo de agua (ljeii catsua' ndaa), por citar los más comunes. La niña debe aprender ante todo el valor simbólico de lo que representa, y el proceso de abstracción que exige su representación sobre el tejido, lo que significa aprender nociones matemáticas esenciales, específicamente geométricas, a distribuirlas en el espacio conforme a un orden preciso, para dar vida a secuencias significativas en el plano del contenido, o bien en el plano propiamente estético. Pero dado que no toma apuntes ni ejecuta diseños previos, la niñita aprende a memorizar antes que a representar las figuras, a partir, obviamente, de las más simples; es decir, las llamadas primeras figuras (ljeii na yolcuch' иu). La primera figura que la niñita aprende a tejer es casi siempre una especie de escarabajo de agua (catsua' ndaa) compuesto de dos triángulos. La serie numérica de la composición prevé una pauta relativamente fácil de hacer que va del uno al cinco (primer triángulo) y viceversa, del 
cinco al uno (segundo triángulo). La pequeña empieza tejiendo en la trama uniforme un hilo colorado, luego dos, tres, y luego vuelve a comenzar la serie dejando un espacio en el tejido. Esto se da, normalmente, hacia los seis años, pero todavía antes ya debió aprender a tejer una trama de color uniforme. No todas las niñas llegan, a través de los años, a tejer los símbolos más complejos, esto depende de su capacidad cognitiva. De hecho, de acuerdo a lo que nos dijo Odilón acerca de las tejedoras ancianas que trabajan con él, ellas aprendieron, tejiendo, a contar, a medir, a hacer operaciones matemáticas complejas y diseños mentales geométricos admirables. Las tejedoras ancianas, consideradas como verdaderas artistas, con frecuencia no conocen ni la escritura -menos la de los números- ni la lectura. El aprendizaje se da por imitación y bajo la tutela de tejedoras más expertas, luego de los primeros “juegos” que la niña realiza junto a la madre o a una hermanita un poco más grande. Mat'iaa na mawa jnom ndaa quiaa nts 'aa (veo cómo tejen, luego lo hago), es una de las respuestas más comunes, cuando se pregunta a las niñas cómo es que aprenden. La enseñanza de la técnica va acompañada por las estrategias para componer las figuras-símbolo. El conocimiento, de inmediato es practico-simbólico, concreto y abstracto. Este aspecto totalmente peculiar de la educación amuzga nos parece de gran interés porque pensamos que puede ser una de las razones que explican las extraordinarias competencias matemáticas y geométricas en sujetos que no tienen escolaridad y que nosotros, con no poca arrogancia, frecuentemente los definimos como analfabetas. Otro aspecto peculiar de esta educación es la espontaneidad. No existe un momento preciso en el que se decide que la pequeña deba aprender a tejer. Se empieza a tejer como jugando, imitando a la mamá. Lo que interesa destacar es que se trata de una educación formal que empieza como juego y surge de la misma niña cuando pide aprender más y mejor. Pero también es cierto que a las niñas se les deja muy libres y que prevalece el proceso de autoaprendizaje. La pequeña, desde los dos o tres años, juega con los hilos, con las madejas, imagina tejer con pedacitos de madera que transforma en pequeños telares, hasta cuando ya no pide explicaciones y no acepta que le preparen su proprio telarcito. El momento inicial no equivale a nuestro "primer día de escuela", porque es espontáneo y lúdico aún cuando se inscribe en un proceso formativo que podemos ver como formalizado, en cuanto se prevé para todas las niñas e implica la adquisición normalizadora de símbolos, instrumentos y estrategias 
mentales. Más aún, requiere de la interiorización de un universo cultural, de una espiritualidad y de un conjunto de saberes concretos. Las pequeñas tejedoras deben conocer el valor cultural e identitario que el tejido tiene para el pueblo nomndaa; el pueblo que proviene de las islas de medio del océano, el pueblo que dice palabras de agua ${ }^{12} \mathrm{y}$ que posee un pensamiento geométrico. Tejer significa llegar a ser, poco a poco, conscientes del papel social y cultural, además de económico, que esta práctica posee. En resumen, la niña que se dispone a tejer debe ser ya consciente de que se adentra en un complejo sistema de valores, de acciones y comportamientos que la vinculan con su comunidad. Por ejemplo, no puede tomar ciertos alimentos que según las creencias de los amuzgos, podrían comprometer la calidad del trabajo. Más iportante es pedir la inspiración a la Virgen o a Jesús, antes de iniciar un trabajo complicado, porque el conocimiento perfecto de los procedimientos no garantiza la calidad del resultado. Sucede que esté ahí duende, ese impulso creativo que teje "arte" cuando las manos de las tejedoras se hacen "soñadoras", y que hace que los colores no se peleen y que los hilos se dejen tejer. Entre los Tzjon Non, nos explica Odilón, el negro casi no se usa, porque una mirada feliz raramente busca una tonalidad tan oscura. El blanco simboliza la pureza, el azul lo infinito del cielo, el verde la naturaleza de los bosques en las cañadas de la sierra. El amarillo es el sol, el púrpura de la cochinilla del caracol la nobleza, el rojo significa protección, el color del café recuerda el color de la "madre tierra". Es así que se plasman las emociones.

Pude constatar que las madres y las abuelas dan a las niñas pequeños regalos para estimularlas a aprender el tejido, pero jamás se trata de una solicitud expresa, ni menos de imposición, porque en tal caso el trabajo se resentiría. La madre muestra a la niña cómo se puede crear un pequeño tejido para vestir a la muñeca, mientras le ofrece un regalo. Luego le indica la posición, cómo debe sentarse en tierra sobre su petate (estera) de fibras vegetales. Y le habla de las pequeñas figuras -las más simples-, de cuántos hilos necesita, cómo organizarlos, cuántos números deberá tener en mente. Siempre es la niña la que pide poder crear las figuras e insiste para que le enseñen este arte: “kee ts'o" (mi corazón desea tejer), dice la niña a la madre o a la abuela, antes de comenzar. Si la niñita no quiere

\footnotetext{
${ }^{12}$ Nomndaa significa "palabras de agua".
} 
aprender el tejido, buscará realizarse en otra tarea, trabajará en el campo o irá a la ciudad a buscar otro trabajo, aunque esto sucede raramente; sólo quien quiere, en suma, y lo escoge como vocación, será encaminada hacia el tejido. Esta práctica ayuda a las niñas a hacerse responsables de sus propias decisiones y a escoger o experimentar instrumentos y estrategias de autoaprendizaje. De aquí la posibilidad de reconocer, desde sus primeros años de práctica un cierta diferencia de estilo. Con mucha frecuencia las tejedoras adultas piden ayuda e inspiración de lo alto y a veces son las madres quienes invocan fuerzas sobrenaturales, cuando la niña se muestra renuente a introducirse en el tejido. Con frecuencia las abuelas se lamentan de que la escuela las aleja de este arte que para ellas es la única formación verdadera; pero también es cierto que este trabajo permite a las niñas cubrir los gastos de la escuela. En fin, es la pequeña tejedora la que busca su proprio estilo de aprendizaje; la madre la apoya y la acompaña, pero desde el inicio, me asegura Odilón, se notan diferentes formas de aprender. Normalmente sólo las niñas que empiezan a tejer alrededor de los seis años o antes, llegan a ser expertas tejedoras, mientras que las que empiezan en torno a la adolescencia tendrán dificultad para crear las figuras más complejas. Es también necesario afinar ciertas capacidades físicas, adquirir una posición que permita cierta resistencia y ejercitar una determinada fuerza con los brazos poniendo correctamente, además, los pies en el suelo. Esto es fundamental para estirar bien la urdimbre, para que el tejido mantenga los lados alineados y uniformes. Para esto los métodos y las estrategias son diversos. No debemos olvidar, de hecho, que la figura no es simplemente la representación inerte de un objeto o de un animal: es un símbolo que contiene la energía vital. Y es justamente la niña quien al ejecutarlo le da vida. No existe un ejercicio orientado al aprendizaje. El hacer tiene como fin hacer cualquier cosa, y esta cosa es el objeto y también la acción. Es una educación activa, colaboradora y concreta, y también densamente simbólica. Se trata de una operación cotidiana, normal, pero al mismo tiempo mágica y extraordinaria. Aquí lo cotidiano y lo extraordinario se confunden, lo maravilloso y lo normal son dos formas de observar la realidad. Dar vida a una figura es un acto creativo maravilloso y normal. Una vez creada, la figura no nos pertenece, porque tiene su propia carga vital que entra en comunicación con toda la energía del mundo. De aquí surge una actitud que no obstante su fuerza poética, es humilde. La figura es algo vivo, se pertenece a sí misma y nosotros simplemente debemos 
cuidarla, como cuidamos de todas las cosas hechas por el Creador; pero las figuras están vivas, participan de lo divino. La energía vital envuelve a la niña, deviene el vehículo para que fluya en los tejidos que aprenderá a elaborar. Habilidad, inteligencia, creatividad, fantasía, humildad y responsabilidad son los valores que la educación amuzga trata de promover mientras se teje. En suma, quien quiere devenir o llegar a ser tejedora experta, y por tanto diseñar, sobre el telaje, figuras complejas, necesariamente deberá pasar por esta sabiduría. El aprendizaje del tejido implica un refinamiento gradual, no sólo técnico, sino también estético y espiritual. Luego de aprender a ejecutar las figuras pequeñas, viene el segundo nivel que consiste en la composición de las figuras-símbolo que representan a las flores (liaa') y a las mariposas (cand $\underline{a a}$ ), para alcanzar, hacia los 12 ó 15 años el tercer nivel: el de las grandes figuras (ljeii t'ma), lo que implica, para cada una, la unión concertada de diversas partes y que, comúnmente, son ricas en detalles. Son las que Odilón define como grecas, aún cuando a nuestros ojos no tienen nada que ver con el imaginario iconográfico de la antigua Grecia. Se trata de ramos organizados de manera muy compleja, de hojas y flores que simbolizan el agua y las montañas (nttee' ljeii ljaa' $n t s c w i$ ') y que normalmente van representadas en la parte superior del huipil, a la altura del seno, llamadas en español pecheras, pectorales. Tales figuras-símbolo decoran normalmente los vestidos de fiesta y de ceremonias. Se componen de la unión de pequeños detalles asimétricos que requieren contar y memorizar los hilos de los diversos colores destinados a las numerosas y pequeñas formas que, a su vez, difieren tanto por su dimensión como por su tonalidad, posición y, naturalmente, su significado simbólico. La elección de los colores en la ejecución de las figuras requiere del contexto natural, pero se da también una clara intencionalidad estética. Escuchando las explicaciones de las tejedoras nos dimos cuenta de que existen, sustancialmente, dos grandes categorías de colores: los fuertes y los tenues. Cada tono tiene luego diversas tonalidades que la niña debe saber reconocer. La elección y la combinación responde, sin embargo, más a criterios de elección autónomos que a reglas precisas socioculturales, aún cuando en las comunidades de los Tzjon Non llevar un huipil con flores de vivos colores es señal clara de intenciones seductivas. El resultado deberá ser un huipil que: "waando' ts'o", que está vivo en el corazón tanto de quien lo tejió, como en aquel de quien lo observa. Las tejedoras acostumbran aproximarse a las madejas de hilo antes de decidir el tipo de 
ejecución que llevarán a cabo para ver si combinan ciertos colores: Xjee nc’iaa "son compañeros", es decir, van de acuerdo cuando al juntarse se ven bien. Hay grupos de colores que son amigos entre ellos. Son ellos los que debe juntar la tejedora. En fin, al interior del mismo grupo de "colores amigos", hay algunos que "se unen" más que otros, hay tonalidades que, unas junto a otras se "despiertan", mientras otras permanecen "adormecidas". Se da el caso que un color encendido "alimenta" a otro más tenue, pero puede suceder lo contrario, que "peleen" uno con otro. La convivencia de los colores en un tejido habla de las personas que los eligieron y los juntaron: es muy importante que resalte la alegría de la tejedora, porque como reza un dicho amuzgo, "se empieza a tejer cuando el corazón canta de felicidad”. Con el tejido, la niña aprende a medir las distancias, a contar los hilos y tener presente el número de acuerdo al color, mientras que une en un conjunto armónico y significativo a los diversos símbolos que compondrán a una única figura. La estrutura de tal decoración es compuesta, desde el momento que implica la ejecución de pequeñas partes, que sólo sucesivamente irán dando vida al significado último. Se trata de un aprendizaje complejo porque requiere el ejercicio de diferentes tipos de inteligencia al mismo tiempo y de aproximaciones al conocimiento que nosotros consideraríamos lejano desde un punto vista epistemológico: matemática, estética, espiritualidad, moral, mitología.... La construcción de una figura grande requiere de la conciencia que las pequeñas partes ya poseen, con la estructura geométrica y con una proporción aritmética, un valor simbólico que debe ser coherente, según la cosmogonía amuzgo, con el sentido general de la figura completa, que es otra respecto a los significados de sus partes, aunque las contenga. Se trata de una educación integral que mientras afina técnicas y habilidades, profundiza en la filosofía y la religión amuzgo. Es conocimiento práctico, y al mismo tiempo, abstracto que impone, poco a poco, una profundización espiritual en torno a las relaciones que marcan la trama de lo humano. Pero también es conocimiento histórico porque narra la llegada de la población nomndaa -como ellos mismos se difinen- desde lejanas islas dispersas en el corazón del océano (ndyuaa xenncue). Es raro, y como con frecuencia sucede en el México profundo, surrealista, que las palabras de agua utilicen símbolos y diseñen figuras (ljeii) que conforman un "lenguaje geométrico". Ljeii significa, al mismo tiempo, figura y símbolo, porque es un término que alcanza a la totalidad, a la unidad espiritual de todas las cosas, 
a su conexión sagrada. Por tanto, si lo real es unidad sagrada, el lenguaje que lo designa tiende preferentemente a organizarse en torno a las conexiones entre significados, más que en torno a sus distinciones. Las "palabras de agua" siguen a "geometrías de la mente" porque aquí la contradicción es sólo un punto de vista temporal e instrumental que fija la mirada en un fragmento de tiempo. Pero el tiempo no tiene fragmentos. "Los fragmentos son un engaño de la lógica europea, el tiempo es circular, cíclico, infinito, porque acompaña la respiración de Dios", me dice el coordinador de los maestros indígenas de Oaxaca, el maestro Aurelio.

\section{El tiempo se teje en forma de espiral}

Entre los Tzjon Non, lo que cuenta no es la fragmentación especializada del saber, sino la totalidad que implica, para cada acción y cada símbolo, una exigencia de complejidad de ese universo cultural. "Los símbolos son sagrados -nos explica una joven madre inclinada sobre el pequeño telar de su niña- porque poseen energía”. Le pregunto si se refiere a las figuras o a las palabras que designan. "A ambas, me responde, porque el símbolo expresado en forma de figura tejida o en forma de palabra vive gracias a su fuerza vital". Le pido que me explique el significado de los símbolos más usados. "El aro representa el cielo y simboliza el infinito. En la figura del caracol el arco designa, al mismo tiempo, el infinito, el tiempo que se mueve y el universo. Las flores representan el sentimiento del amor y de la gracia femenina, y es por este motivo que se tejen en los trajes de las esposas. El símbolo del agua, que se traduce en forma de zigzag, es muy importante porque se refiere al origen de los amuzgo y a su lengua nomdaa que significa palabras de agua. Luego están muchas figuras de animales que hablan de los nahuales, los espíritus que se refieren a los hombres"... pero de esto no hablan nuestras tejedoras porque pertenece ya al terreno prohibido de lo sagrado. Llegué a la conclusión de que el arte del tejido representa, al mismo tiempo, un método educativo y una técnica. Entendemos por método educativo un conjunto coherente de procedimientos y de estrategias regidas por normas que, a su vez, están regidas por principios. Se trata, por 
tanto, de un sistema conceptual. Por técnica entendemos una competencia artística o artesanal transmisible de generación en generación que se sirve de instrumentos conceptuales o bien de modelos de ejecución, pero también de soportes materiales, propiamente técnicos, como lo es el telar de cintura. El modelo de ejecución es el procedimiento con el que se teje en el telar un huipil. Pero el procedimiento pertenece al método de aprendizaje de la técnica. Y sin embargo, este arte sutil es también tecnología, o bien reflexión sobre la técnica, porque implica un amplio campo de relaciones tanto con el mundo simbólico como con el ambiente natural y el contexto social. Por otra parte, presupone una práctica compleja de cuentas aritméticas y de medidas geométricas. Por esto sostenemos que el procedimiento determina la recíproca dependencia entre método y técnica. El tejido representa un tipo de lenguaje visual porque las figuras-símbolo se colocan en una estructura - especie de gramática- que organiza la posición de las formas y da un orden lógico y narrativo a sus elementos. La educación de las niñas amuzgo ve más a la sabiduría que a la adquisición de un saber pragmático, que sin embargo contiene. Es importante que las niñas Tzjon Non aprendan a tejer porque tienen necesidad de vestirse, porque en el telar aprenden a "tejer" su propia e individual personalidad dentro de una filosofía de vida que es compleja y ancestral. La belleza de sus hechuras hablará de su misma belleza que es signo de elegancia e interpretación profunda de valores morales, sociales, religiosos, y de creatividad, fantasía y buen gusto. Elegancia, fertilidad, belleza y conocimiento son los fundamentos éticos de la formación de las niñas entre los Tzjon Non.

"Un huipil es hermoso cuando expresa una gran riqueza espiritual, cuanto contiene muchos símbolos cuyos colores son, al mismo tiempo, coherentes en el significado y en la combinación cromática", me explica Odilón. Las niñas se visten de belleza y de espiritualidad. La precisión del procedimiento, la regularidad de las tramas y la estabilidad de los códices no ocultan su creatividad, sino que representan instrumentos de expresión -y también de construcción- identitaria no sólo en el sentido comunitario y cultural, sino sobre todo individual. El tejido es un fenómeno estético no sólo porque es bello o porque logra expresar un objeto artístico, sino sobre todo porque contiene y alimenta una gran densidad relacional (cfr. Lévi-Strauss 2008). Y dado que es relación 
con lo creado, alcanza lo sagrado (cfr. Bateson y Bateson 1987). La naturaleza es un todo con las personas, no existe ninguna relación de dominio, de goce o de protección. No existe la alteridad: El ser humano es naturaleza. La misma energía vital que fluye en la mente y en el corazón del hombre, hace correr a los ciervos en el bosque, mueve la savia de las hojas, endereza las ramas de los árboles hacia el cielo, brota en el trino de los pájaros y hace parir a las mujeres. Éste es el saber que se construye con el tejido; un saber que comprende un conocimiento pragmático y cotidiano, pero que trasciende y alcanza a lo lírico. Así, su conocimiento asume poco a poco un camino circular y una naturaleza holística, total, porque se refiere a todo el espacio social y cultural que habitan los Tzjon Non y que es continuación del espacio natural, que a su vez, vibra de energía espiritual. Cuando la niña, en sus primeros lances aprende a diseñar flores, viento, maíz y tortillas, no representa sólo a los elementos que llenan su vida diaria, sino a la misteriosa y sutil energía espiritual que de ellas se difunde. Todo esto tiene que ver con la forma educativa y con el proceso de construcción del conocimiento Tzjon Non. En este sentido, el nuestro es un experimento epistemológico: recogimos información de acuerdo a criterios y métodos de investigación etnográfica, a la luz de una epistemología de la formación que ve, en la educación, un proceso relacional, multifactorial, multidireccional que, como lo hemos escrito reiteradamente, inicia la responsabilidad última de quien la recibe.

Los amuzgos en general, y los Tzjon Non en particular, tienen su proprio sistema para contar definido "luaatsa to", por parejas y nodos. Es un sistema de pensamiento matemático que no se basa en la unidad, es decir, no considera, en el esquema de procedimiento de la preparación previsto para el tejido, a los hilos singulares o aislados. Así, contando y alternando pares y dispares en relación a los nodos, se llega a un proceso de abstracción complejo. Las niñas empiezan a contar de dos en dos, y cuando ya tejieron cinco veces dos hilos, se hace un nudo pequeño. Cinco nudos pequeños componen un nudo grande. Para hacer un huipil de adulta (lienzo de ocho o nueve metros de largo y de cuarenta centímetros de ancho) se requieren seis nudos grandes y sólo dos para uno de niña. Esto significa que la trama será de seis vueltas veinticinco parejas de hilos. Esto sucede para “tsei' jda' ndyu jnom”, o sea para ordenar en el telar su trama. Sobre la base de multiplicar cinco pares de hilos se prepara la trama de un huipil grande o chico, 
variando, desde luego, la cantidad de nudos, pero conservando el esquema numérico de las proporciones. Es claro que preparar el mismo número de nudos sobre un telar pequeño, de niña, significa obtener un tejido muy denso y rígido. Es importante, por tanto, obtener la blandura justa, pero también sin rigidez.

Si en la preparación de la trama los hilos se enlazan entre pares y dispares por medio del bastón horizontal que se usa luego de haber distribuido los hilos de los nudos en pares y dispares, en la composición de las figuras, las tejedoras cuentan los pares y los hilos escogidos. Cada figura responde a una precisa construcción lógica que se basa en un particular sistema matemático de cuentas aritméticas y de construcción geométrica. Deduje, por ello, que la unidad básica de esta forma de contar es el par, que se sostiene con el nudo pequeño, y sucesivamente, con el grande. Se trata de una secuencia lógica progresiva y unidireccional que construye la numeración por agrupación de los hilos que se van sumando a los pequeños añadidos de cinco pares hasta llegar al grupo de veinticinco pares. La niñita debe aprender a pensar, no sólo en los diseños que está tejiendo en aquel momento, sino en su posterior integración con los que se tejerán o ya se tejieron, en fin, con la reunión de diferentes telas con las que se teje un huipil. Una vez más, aunque de manera diferente, aparece la integración armónica de la parte con el todo, como si fuera un trasfondo hologramático inconsciente; esa "información global” que permite conectar la parte con el todo de manera significativa. Una sola parte representaría un holograma del todo, porque posee el signo característico del universo global al que pertenece $^{13}$. Se ha dicho que es una integración geométrica, pero también aritmética y con fuertes consecuencias religiosas. No es un ejemplo claro el símbolo que representa un animal: un águila, un ciervo, un jaguar o sólo su huella: son signos del nahualismo ${ }^{14}$. Las figuras tejidas en los huipiles dan una interpretación de la realidad espacial que circunda

\footnotetext{
${ }^{13}$ Ken Wilber, estudioso estadounidense y editor de la revista ReVision, coordinó, al inicio de los años ochenta, la publicación de: The Holografic Paradigm and other Paradoxes: Exploring the Leading Edge of Science. Ahì se presentan las principales aportaciones de D. Bohm, K. H. Pribram, F. Capra. Si Bohm ha insistido en el holograma como nuevo modelo de descripción de la realidad, Pribram le proporcionó el elemento central de estudio del cerebro, particularmente del conocimiento humano en sus múltiples manifestaciones: del aprendizaje a la percepción, de la intuición a los "desórdenes" cognitivos, sin descuidar las "paradojas" del pensamiento.

${ }^{14} \mathrm{He}$ abordado este tema en mi relato Nahual, que recoge, de forma narrativa, testimoios directos de lo que sucedió.
} 
a la pequeña tejedora, así como de las relaciones matemáticas y de las filosóficas, o más ampliamente culturales, que la caracteriza. Pero dado que en la filosofía amuzga las figuras están animadas por una energía vital, las representaciones mentales no sustituyen a la realidad, como sucede en nuestra geometría, la reproducen concretamente y con ello amplían los movimientos espirituales. La conceptualización del espacio que se traduce en bellísimas decoraciones de los tejidos amuzgos, es una forma de organización, expresión y construcción del conocimiento. La figura ljeii es un símbolo y un concepto, sentimiento y emoción. El conocimiento que se obtiene tejiendo es holístico porque alcanza múltiples saberes conectados entre ellos: de la representación de objetos cotidianos a su utilización, hasta las construcciones simbólicas relacionadas con las costumbres sociales, con la naturaleza, la espiritualidad, la cosmogonía.

\section{Conclusiones}

Una característica original de esta educación especial reservada para las niñas es la relación estrecha entre el hacer y el pensar; podríamos decir que el tejido es pensamiento en acción, abstracción concreta. Aquí lo cotidiano llega a ser extraordinario porque está invadido de sacralidad: la norma es extranorma, en el sentido que existe en sí, pero al mismo tiempo, fuera de sí, es natural y por tanto, paradójicamente, sobrenatural. Pero el conocimiento holístico que se desarrolla al tejer constituye un todo con la filosofía educativa que forma a estas niñas. Como el arte de los huipiles, la educación debe y sólo puede ser integral, referirse a la totalidad de la experiencia existencial, no puede tener sólo fines pragmáticos porque el resultado de las acciones siempre tiene un lado simbólico: Cha'tso ne quii' ljeii” (todo es símbolo), dicen con frecuencia las mujeres amuzgas. Más aún, es comunicación con lo sagrado: son muchas las figuras que reflejan una estrecha relación simbólica con la naturaleza y con el concepto de tiempo, de Dios, de vida. Los símbolos más antiguos (lijeii t'quiee) conservan un significado mitológico y cosmogónico, "tienen alas" -comenta Odilón- expresan el deseo de conservar y transmitir el conocimiento ancestral. Representan verdaderos documentos de la historia y 
los orígenes del pueblo nomndaa. Pero esta función práctica no está separada de la dimensión de la sacralidad porque ljeii”, como símbolo, no designa sólo al objeto al que se refiere o al mito o la historia, sino que es expresión de la energía divina que dio vida al objeto, al mito, a la historia. Tejer significa participar en este flujo que es espiritualidad y vida. Es reproducirlo mientras se lo representa. Es acompañar el fluir del tiempo, dándole significados. Tejer bien es mucho más importante que producir algo bien hecho del tejido normal y de las figuras precisas cuyas partes coinciden en los puntos exactos según la escala de colores previstos y de los cálculos hechos; porque el tejido no es sólo una técnica, sino la expresión de una sabiduría. Los dedos finos de las niñas Tzjon Non deben aprender a moverse de acuerdo a la cadencia sagrada de un tiempo ancestral. Es dialogar con el infinito. El tejido de las figuras antiguas "lo hace quien de verdad sabe", afirma odilón. La niña utiliza sus competencias intelectuales y culturales para incorporar en un antiguo universo de significados nuevos contenidos a través de imágenes nuevas. Pero la cosa más interesante es que tal adquisición no es pasiva, ni imitadora o simplemente decorativa. Es estructural, se trata de una reestructuración del cosmos tradicional que prevé la asimilación de nuevos símbolos dentro de rutas de significado que dialogan con los antiguos. El mundo está cambiando, pero no cambia su cosmogonía. El encuentro con las diferencias se interpreta, comprende y se ajusta en un universo de símbolos coherente, que es el antiguo.

He llegado a la conclusión de que el tejido es una formidable mnemotécnica que tiene una función cognitiva y metacognitiva. De hecho, la mente de las niñas amuzgas se educa para concebir la construcción del saber como un ir en busca de las relaciones que unen las diferentes unidades de una estructura. Mediante el tejido la niña adopta y pone en práctica un principio de contextualización según el cual la creación de una figura no puede realizarse sino concibiéndola como parte de un contexto. El procedimiento mental es geométrico, pero la estructura que conecta es espiritual. Cada figura es un símbolo, vibra de energía vital, participa de lo divino y comunica lo cotidiano con lo trascendente. La construcción de las figuras, sobre todo de las más complejas, implica la mentalización preventiva de las estructuras conectivas -que, repetimos, son geométricas-y que las determinan. Esto significa que la tejedora aprende a distinguir los nudos que hacen 
interdependientes las partes de una imagen, y la imagen misma en relación con otras imágenes. Pero las relaciones de significado, que se expresan geométricamente, tienen consecuencias simbólicas de gran complejidad. La relación estructural que arregla geométricamente la figura sobre la trama se compone de simbiosis con otros nexos que, a su vez, se mezclan con el tejido cultural de ese pueblo. La relacionalidad es constitutiva de la identidad antropológica de la comunidad amuzga. La formación respeta, sin que haya continuidad, a la naturaleza de esa cultura: no existen dicotomías, ni mensajes ambiguos o contradictorios, porque todo es símbolo. Todos los valores van en la misma dirección: producir bienes materiales es, al mismo tiempo un acto sumamente espiritual, sumergirse en lo contingente es elevarse hacia lo trascendente, la mano es la mente, la técnica es una forma de pensamiento.

Las pequeñas tejedoras adquieren y perfeccionan sus propias habilidades culturales, mnemotécnicas, sensoriales y cognitivas mientras tejen; o bien aparentemente lo hacen en una sola práctica. La matemática, y en su interior, la geometría, representan claves de lectura del mundo, construcciones culturales, sistematizaciones simbólicas. La matemática amuzga se basa en un sistema aritmético diferente, del que la escuela bilingüe, presente en las comunidades indígenas, debería tomar cuenta para no imponer un sistema simbólico que pertenece a otras claves de lectura, otras construcciones culturales, otros ordenamientos simbólicos. Porque la escuela es escuela cuando, antes de plantearse el problema de lo que ha de enseñar, se pone ante el problema -y lo resuelve- de cómo y qué cosa aprender. De no ser así, la intercultura es sólo una ficción que esconde un colonialismo inconsciente.

\section{Referencias bibliográficas}

Anaya, Graciela. 1987. “Lenguas De México: Su Clasificación”. México indígena, 17, año III, julio-agosto 1987: 3-7.

Bateson, Gregory y Mary Catherine Bateson. 1987. Angels Fear. Toward an Epistemology of the Sacred. New York: Macmillan. 
Blancas, Elsa M. 2010. “La comunicación en el aula: niños indígenas bilingües y maestro monolingüe en español". Lengua y cultura en procesos educativos: investigaciones en Oaxaca. Coords. Marcela Coronado Malagón y Patricia Mena Ledesma. Oaxaca: UPN. 29-47.

Escolano Benito, Agustín y Anita Gramigna (coords.). 2004. Formazione $e$ Interpretazione. Itinerari ermeneutici nella Pedagogia Sociale. Milano: Angeli.

Frutiger, Adrian. 1981. Signos, símbolos, marcas, señales. México: GG.

Gadamer, Hans Georg. 1972. Verità emetodo. Milano: Vompiani. Marietti. 1973. Ermeneutica e metodica universale, a cura di U. Margiotta. Genova:

Geertz, Clifford. 1987. Interpretazione di culture. Bologna: Il Mulino. . 1995. Oltre i fatti. Bologna: Il Mulino. 2001. Antropologia e filosofia. Bologna: Il Mulino.

Gramigna, Anita. 2013. Nahual. Ferrara: Editrice Voltacarta.

Instituto Nacional de Estadística, Geografía e Informática. 2001. Censo General de Población y Vivienda 2000. México.

Lévi-Strauss, Claude. 2008. Cristi di oscure speranze. Roma: Gransasso nottetempo. . 1978 [1973]. Anthropologie structurale II, Paris: Plon. Trad. it. Antropologia strutturale due. Milano: Il Saggiatore.

Stewart, Cloyd y Ruth Stewart. 2000. Diccionario Amuzgo de San Pedro Amuzgos Oaxaca. México: Istituto Linguistico de Verano en Coyocàn.

Valleriani Antonio. 2003. Trame dell'alterità. Studi di pedagogia interculturale nel mondo globalizzato. Teramo: Edigrafital.

Vattimo, Gianni. 1989. Ética dell'interpretazione. Torino: Rosemberg \& Sellier. 1994. Oltre l'interpretazione. Roma-Bari: Laterza.

Wilber, Ken (coord.). 1993. The Holografic Paradigm and other Paradoxes: Exploring the Leading Edge of Science. Boston: Shambhala Pubns. 